\title{
Sustainability Dynamics
}

\author{
Rainer Stark and Kai Lindow
}

\begin{abstract}
Value creation ensures societal prosperity. At the same time, Sustainable Development determines the future of global human wellbeing. Both aspects are based on profound environmental, social and economic mechanisms - and both aspects are closely linked. The Sustainability Dynamics Model describes the direct and indirect effects of value creation together with the three dimensions of Sustainable Development. This contribution introduces and defines the Sustainability Dynamics Model. The effects and dynamics are exemplarily shown. Eventually, the link to circular economy is drawn. In the future, the Sustainability Dynamics Model can be used as a control model in order to predict consequences of value creation towards environmental, social and economic sustainability.
\end{abstract}

Keywords Sustainability dynamics model - Sustainable development - Circular economy $\cdot$ Value creation $\cdot$ Consumption and production

\section{Dynamics in Value Creation and Sustainable Development}

Value creation is a key element for ensuring societal prosperity. In the classic sense, value creation is equated with industrial production to meet the needs of society (cp. Fry et al. 1994). Likewise, Sustainable Development (cp. WCED 1987) determines the future of global human wellbeing. In the year 2015, the United Nations defined Sustainable Development Goals (UN 2015) and targeted them to the year 2030 (Fig. 1).

\footnotetext{
R. Stark $(\bowtie)$

Chair of Industrial Information Technology, Institute for Machine-tools and Factory Management, Technische Universität Berlin, Berlin, Germany e-mail: rainer.stark@tu-berlin.de

K. Lindow

Technische Universität Berlin, Berlin, Germany

e-mail: kai.lindow@tu-berlin.de

(C) The Author(s) 2017

R. Stark et al. (eds.), Sustainable Manufacturing, Sustainable Production,
}

Life Cycle Engineering and Management, DOI 10.1007/978-3-319-48514-0_2 


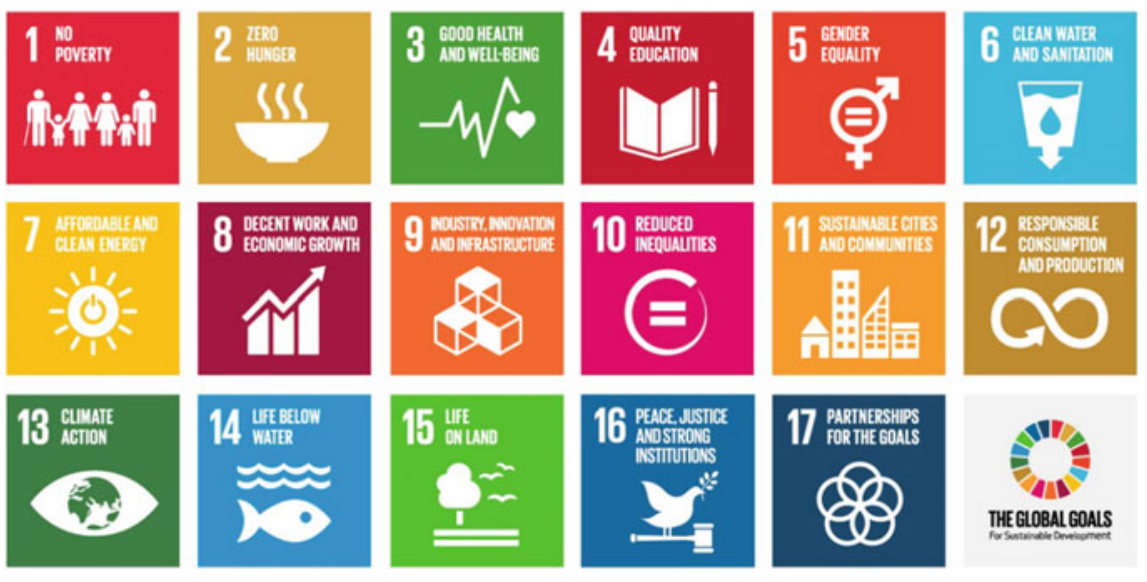

Fig. 1 The United Nations Sustainable Development Goals at a glance (UN 2015, image source http://www.un.org/sustainabledevelopment/sustainable-development-goals)

On the 25th of September 2015, 193 countries of the United Nations General Assembly adopted a set of sustainable development goals to end poverty, protect the planet and ensure prosperity for all as part of a new sustainable development agenda. Following the adoption, United Nations agencies have supported a follow-up campaign on the part of several independent entities, among them corporate institutions and international organizations. The campaign, known as Project Everyone, introduced the term global goals. Its intention is to help communicate the agreed upon Sustainable Development Goals to a wider constituency.

For the first time, sustainable consumption and production patterns are specifically mentioned among the seventeen goals (Fig. 2, UN 2015).

The particular claim of goal 12 is to reach out for sustainable consumption and production at "doing more and better with less." The scope ranges from macro- to microeconomic level, from society to individuals, from degradation to pollution along the whole lifecycle, while likewise increasing quality of life. It involves different stakeholders, including business, consumers, policy makers, researchers and retailers among others. Furthermore, this goal requires a systemic approach and cooperation among stakeholders in the entire supply chain, from producer to final consumer.

Ueda et al. take up the basic idea and elaborate: "in association with globalization and networking, every industry in this century is strongly required to contribute to sustainable development, but no solution can be obtained easily when considering the complexity and instability of the social systems. Additionally, maintaining sustainability often creates a dilemma between values of a whole society and values of individuals [...]. Therefore, to resolve this problem, more attention must be devoted to value creation mechanisms" (Ueda et al. 2009).

In this context, both aspects of value creation and sustainable development need to be combined to form Sustainable Value Creation. The mechanisms included in value creation and Sustainable Development are highly dynamic. 


\section{Goal 12. Ensure sustainable consumption and production patterns}

12.1 Implement the 10-Year Framework of Programmes on Sustainable Consumption and Production Patterns, all countries taking action, with developed countries taking the lead, taking into account the development and capabilities of developing countries

12.2 By 2030, achieve the sustainable management and efficient use of natural resources

12.3 By 2030, halve per capita global food waste at the retail and consumer levels and reduce food losses along production and supply chains, including post-harvest losses

12.4 By 2020, achieve the environmentally sound management of chemicals and all wastes throughout their life cycle, in accordance with agreed international frameworks, and significantly reduce their release to air, water and soil in order to minimize their adverse impacts on human health and the environment

12.5 By 2030, substantially reduce waste generation through prevention, reduction, recycling and reuse

12.6 Encourage companies, especially large and transnational companies, to adopt sustainable practices and to integrate sustainability information into their reporting cycle

12.7 Promote public procurement practices that are sustainable, in accordance with national policies and priorities

12.8 By 2030, ensure that people everywhere have the relevant information and awareness for sustainable development and lifestyles in harmony with nature

Fig. 2 Goal 12 "Ensure sustainable consumption and production patterns" among the seventeen United Nations Sustainable Development Goals (UN 2015)

Firstly, value creation is characterised by flows of information, resources, capital and labour among production systems. Secondly, these flows are realized within socio-economic, natural and sociotechnical systems. Thirdly, value creation runs over two major levels:

(a) The micro-economic level manages e.g. value creation in supply-chain of a product and value creation along the lifecycle of a product) and

(b) The macro-economic level manages value creation of an entire branch and value creation among countries and within regions.

The interaction and interdependencies of Sustainable Value Creation, therefore, lead to a high dynamic among the different systems and their linkages. Value creation activities and services follow three types of interactions as direct and indirect effects between the three major dimensions of sustainability (environment, society and economy): 
1. Causal relations,

2. Magnitude and scale drivers and

3. Latency and timely duration dependencies.

Causal relations describe the determined effects between a solution and its direct and indirect impact on the three dimensions of sustainability (e.g. a new manufacturing solution and its direct impact on the economy, as well as its indirect impacts on society and environment). The direct and indirect impact is determined by the magnitude and scale of a solution's dissemination (e.g. the societal and environmental impact of a solution becomes measurable due to its increasing market share). The effects and impacts have different latencies and time durations (e.g. the societal and environmental impacts of an established solution have a delay and last a certain period of time). The evaluation and description of these dynamic effects is a scientific task and its solution has to however be practical at the same time.

\section{Sustainability Dynamics Model}

The Sustainability Dynamics Model (SDM) is an instrument for describing the direct and indirect effects of value creation solutions on the three dimensions of sustainability and vice versa. Since value creation solutions are the key elements they become the central focus of the model. The three dimensions of Sustainable Development (environment, society and economy) actually represent systems of their own and evolve around the value creation solution (Fig. 3).

Starting from the value creation solution, direct effects between the solution and each sustainability dimension system can be pinpointed:

- The primary effects on the environment are the use and conversion of energy, materials, greenhouse gases etc.

- The primary effect on the society are the improvement of living standards, the use of products, prosperity etc.

- The primary effects on the economy are manufacturing processes, factories, logistics etc.

The primary effects on one dimension system can cause impacts on other dimension systems. In addition to causal effects (e.g. between environment and society), the above-mentioned effects in the levels of magnitude and scale as well as latency and time duration can be observed. In this case, the root causes not only primary impacts on one dimension system but also secondary impacts on the other two dimension systems of sustainability. Mutual spiral effects between the sustainability dimension systems can, furthermore, be caused by the intended primary effects.

The effect of a value creation solution on the dimension systems of sustainability can be defined as an inside-out effect. Even so, cause and effect vary with different 


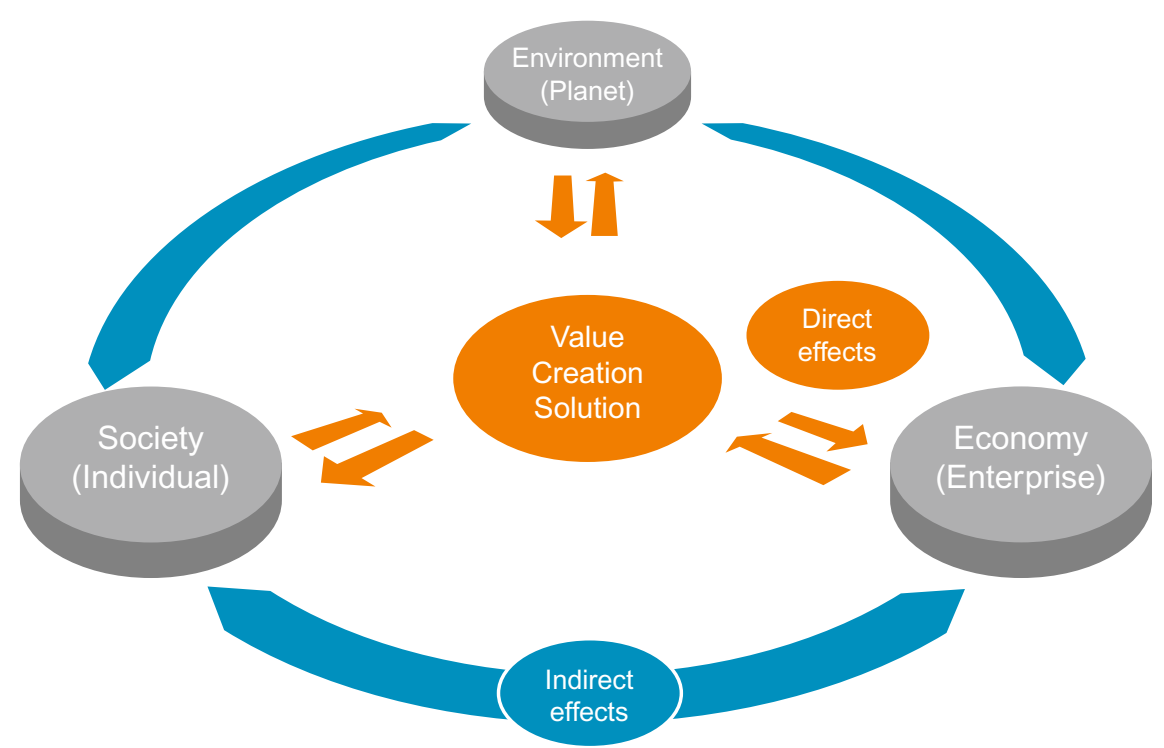

Fig. 3 Introduction of the Sustainability Dynamics Model (value creation solution and their direct and indirect effects on sustainable dimension systems)

value creation solutions and their impact on sustainability, among other factors. The Sustainability Dimension Model allows an opposite contemplation, which is called an outside-in effect. In this case, the cause can be met in any of the three sustainability dimension systems. This leads to a direct impact on the value creation solution and, additionally, to secondary effects on other sustainability dimension systems through the value creation solution.

An example of outside-in effects is found in the sub-goal 12 "Ensure sustainable consumption and production patterns" of the United Nations Sustainable Development Goals (UN 2015). The dynamic effects of sustainable consumption and production play a major role on a macro-economic level, especially in sustainability dimensions and the indirect effects in between. Figure 4 represents the mapping of the eight sub-goals.

In order to illustrate the dynamics in sustainability, the following exemplary goals are revealed:

- 12.2: "By 2030, achieve the sustainable management and efficient use of natural resources" (UN 2015).

- 12.4: "By 2030, achieve the environmentally sound management of chemicals and all wastes throughout their life cycle, in accordance with agreed international frameworks, and significantly reduce their release to air, water and soil in order to minimize their adverse impacts on human health and the environment" (UN 2015).

- 12.5: "By 2030, substantially reduce waste generation through prevention, reduction, recycling and reuse" (UN 2015). 


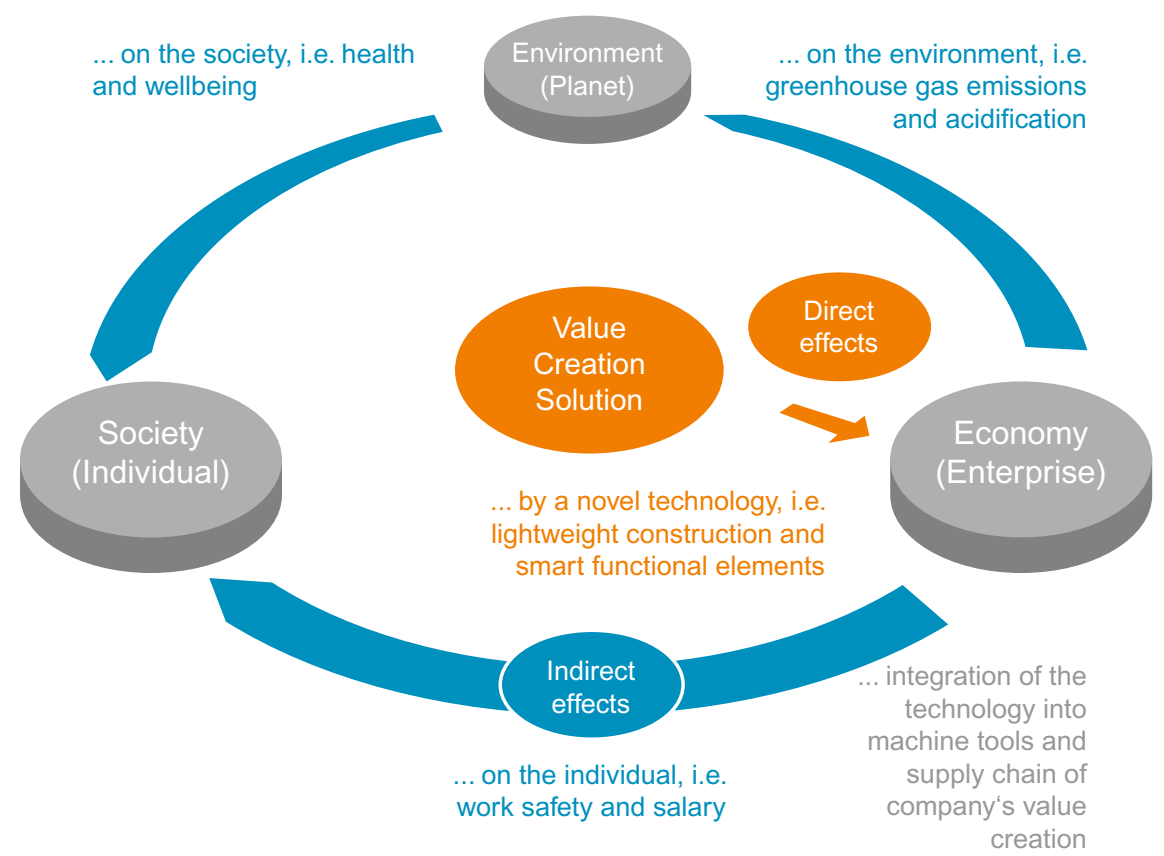

Fig. 4 Mapping of the eight sub-goals of goal 12 "Ensure sustainable production and consumption patterns" of the United Nations Sustainable Development Goals and the Sustainability Dynamics Model

Goal 12.2 focuses on the overall introduction of principles of sustainable development into country policies and programmes. Regarding the Sustainability Dynamics Model, its primary effect lies in the social dimension system. Actions from this dimension system have a direct causal effect on the economic dimension system. Companies within this dimension system have to fulfil sustainable policies and programme demands. That way, the indirect effect is on value creation solutions. Sustainable solutions have to be researched and they need to be applied in manufacturing companies. Depending on the magnitude and scale, an indirect effect on the environmental dimension system takes place and, in return, on the social dimension system on top of that.

Goal 12.4 directly affects the environmental dimension system. The environmentally sound management of chemicals and all wastes throughout their life cycle, along with the significantly reduction of their releases into air, water and soil, together impact both the social and the environmental dimension system at the same 
time. In order to minimise their impacts on human health, sustainable value creation solutions have to be implemented on a large scale and level of magnitude. These effects occur in latency and timely duration dependencies.

Goal 12.5 deals with the generation and management of waste on a micro- and macroeconomic level. It directly affects the economic dimension system. Technologies and techniques from sustainable value solutions should be applied and used in order to reduce and manage waste from industry. At the same time, products and services that are offered in this dimension system have a causal relationship with its use within the social and individual dimension system. That way, prevention, reduction, recycling and reuse solutions all have an effect on the environmental dimension system.

\section{Instantiation of the Model}

The direct and indirect effects along the Sustainability Dynamics Model can be defined as inside-out effects and outside-in effects. These effects can be either observed when the model is read from the inside (sustainable value creation) to the outside (sustainable dimension systems, ) or, vice versa, from the outside the inside. In the following, these two principles are illustrated with two examples.

The first example deals with a novel sustainable manufacturing solution which is based on an innovative manufacturing technology (Fig. 5). This could be gained i.e. by lightweight construction, smart functional elements, improved working accuracy or smart interfaces. The effect on the environmental and social dimension system of the new technology itself is not yet provided. That is, a causal relationship with society and environment can only be found indirectly. However, a direct causal relationship, and in that respect, a direct effect of the new technology, are offered to the economic dimension system. The new technology has to be implemented into a machine tool and into the supply chain. This entails that, a company integrates the solution into their value creation process. Over time, the new solution is in use, indirect effects on the social and environmental dimension system can be found. On the one hand, individuals who are in charge of the new solution are affected i.e. by work safety and salary. Depending on the magnitude and scale of the new solution, the degree of impact on the environmental dimension system is defined, i.e. greenhouse gases and acidification. Furthermore, not only the individual but the whole society is indirectly affected by the environmental impact, i.e. in terms of health and well-being.

The second example deals with the growing awareness among society about sustainable products and services (Fig. 6). In this case, society and individuals demand sustainable solutions. The direct effect is the need for a sustainable value creation solution which can be either a product, a service or a Product-Service System. The solution should provide sustainable principles to the customer, i.e. in terms of emissions, noise, safety, costs, recyclability. The indirect effect is basically on manufacturing companies which develop, manufacture and provide the new 


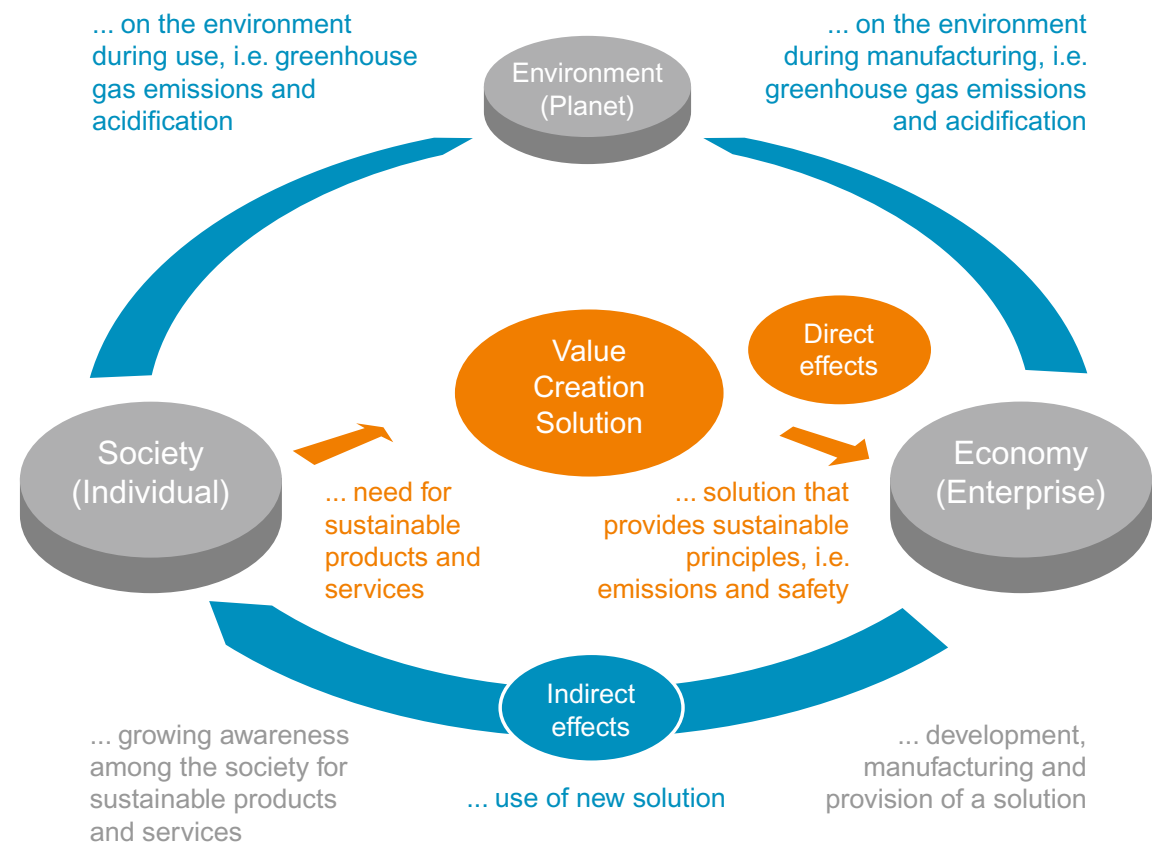

Fig. 5 Inside-out effects of an innovative value creation solution on the economic, social and environmental dimension system

solution to the individual. Depending on the magnitude and scale of the new solution, the impact on the environmental and social dimension system varies, i.e. in terms of greenhouse gas emissions and acidification by manufacturing and use of the solution.

\section{Conclusion}

The notion of Sustainability Dynamics is a new scientific approach which describes the interconnectivity between core dimensions of sustainability and their related internal systems with the system of value creation solutions. The new approach is described within this contribution as a first foundation causal model in pursuit of providing a new basis for describing cross-system sustainability behaviours and influences.

The authors have concentrated on demonstrating the principle power of the model with the help of allocating the sub-targets of goal 12 of the seventeen United Nations Sustainable Development Goals into the causal network of the Sustainability Dynamics Model. This goal 12 represents the only goal amongst the seventeen goals which directly addresses sustainable consumption and production patterns critical for sustainable value creation and manufacturing contributions. 


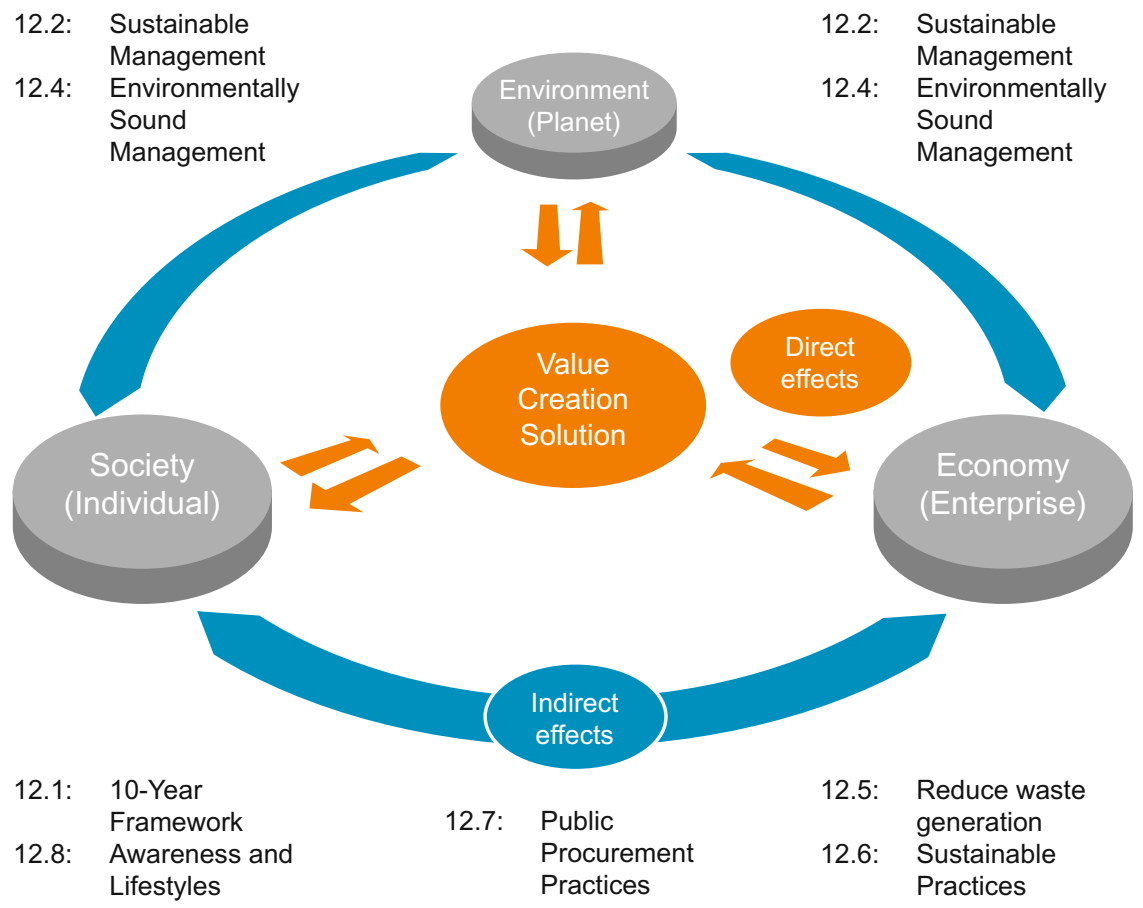

Fig. 6 Outside-in effects of a growing awareness among the society for sustainable products and services on the value creation solution and on the economic, social and environmental dimension system

The Sustainability Dynamics Model for the first time ever enables the visual and qualitative capabilities for showing the interdependencies and causal effects of value creation solutions (e.g. as part of sustainable product development and sustainable manufacturing) with the major systems of the three sustainability dimensions of environment (planet/earth), economy (enterprises) and society (individual). At this point, in time the Sustainability Dynamics Model exists at a foundational level in order to allow high level and principle trade-off discussions and qualitative reasoning.

The next level of the Sustainability Dynamics Model is targeted at fostering and expanding the "dynamic" dimension. That is, principles of the model theory system dynamics (cp. Sterman 2000) will be utilised in pursuit of quantitative prediction capability. From a knowledge and model depth point of view it will be scrutinized which type of model laws can be integrated robustly. At this point in time it is the authors' belief that the Sustainability Dynamics Model bears significant capability to deploy both rule-based dynamic mechanisms as well as big/smart data plug-ins, for the purpose of delivering an increasing level of consequence prediction capability for the contributions of value creation solution towards "measurable" sustainability. 


\section{Outlook}

The major element to transform manufacturing towards "higher sustainability" with respect to global value creation is "resource productivity within a compatible environment" (cp. Bleischwitz et al. 2009). Such target state requires continuous improvements in resource discovery. At the same time, resource productivity remains hugely underexploited as a source of wealth, competitiveness and renewal.

The European Commission started to propose a circular economy strategy (EC 2015) and many business leaders have indeed embraced the circular economy as a path to increasing growth and profitability (Lovins and Braungart 2014). In this manner, the circular economy is gaining increasing attention and offers a potential way for the society to increase prosperity, while reducing dependency on primary materials and energy. In this context, the Sustainability Dynamics Model even now at its infancy stage serves as an enabler for explaining basic connections between value creation and circular economy against the background of sustainable development. Furthermore, correlations and coherences could be explained by direct and indirect effects in terms of causal relations, magnitude and scale drivers and latency and time duration dependencies at a micro- and macroeconomic level.

Future expansions of the Sustainability Dynamics Model, as depicted in Sect. 4 of this contribution, will deliver the potential to serve as one of the core control models of value creation contributions within the circular economy of the future.

\section{References}

Bleischwitz, R., Z. Zhang, and P. Welfens. 2009. Sustainable growth and resource productivity: Economic and global policy issues. Greenleaf Publishing.

European Commission (EC). 2015. Closing the loop-An EU action plan for the Circular Economy. Brussels, 02.12.2015, $\operatorname{COM}(2015) 614$ final.

Fry, T.D., D.C. Steele, and B.A. Saladin. 1994. A service-oriented manufacturing strategy. International Journal of Operations \& Production Management 14(10): 17-29.

Lovins, A., and M. Braungart. 2014. A new dynamic - effective business in a circular economy. Ellen MacArthur Foundation.

Sterman, J. 2000. Business dynamics: Systems thinking and modeling for a complex world. McGraw-Hill Higher Education.

Ueda, K., T. Takenaka, J. Vancza, and L. Monostori. 2009. Value creation and decision-making in sustainable society. Annals of the CIRP 58/2: 2009.

United Nations (UN). 2015. Transforming our world: The 2030 Agenda for Sustainable Development. United Nations Resolution A/RES/70/1 adopted by the General Assembly on 25 September 2015, New York, 2015.

World Commission on Environment and Development (WCED). 1987. Our common future. United Nations General Assembly, Nairobi, 1987. 
Open Access This chapter is licensed under the terms of the Creative Commons Attribution 4.0 International License (http://creativecommons.org/licenses/by/4.0/), which permits use, sharing, adaptation, distribution and reproduction in any medium or format, as long as you give appropriate credit to the original author(s) and the source, provide a link to the Creative Commons license and indicate if changes were made.

The images or other third party material in this chapter are included in the book's Creative Commons license, unless indicated otherwise in a credit line to the material. If material is not included in the book's Creative Commons license and your intended use is not permitted by statutory regulation or exceeds the permitted use, you will need to obtain permission directly from the copyright holder.

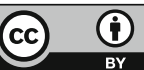

